\title{
LA VIOLENCIA SEXUAL A LA LUZ DE LA LEY DE JUSTICIA Y PAZ: CONCEPTUALIZACIÓN Y ELEMENTOS PARA SU ESTUDIO
}

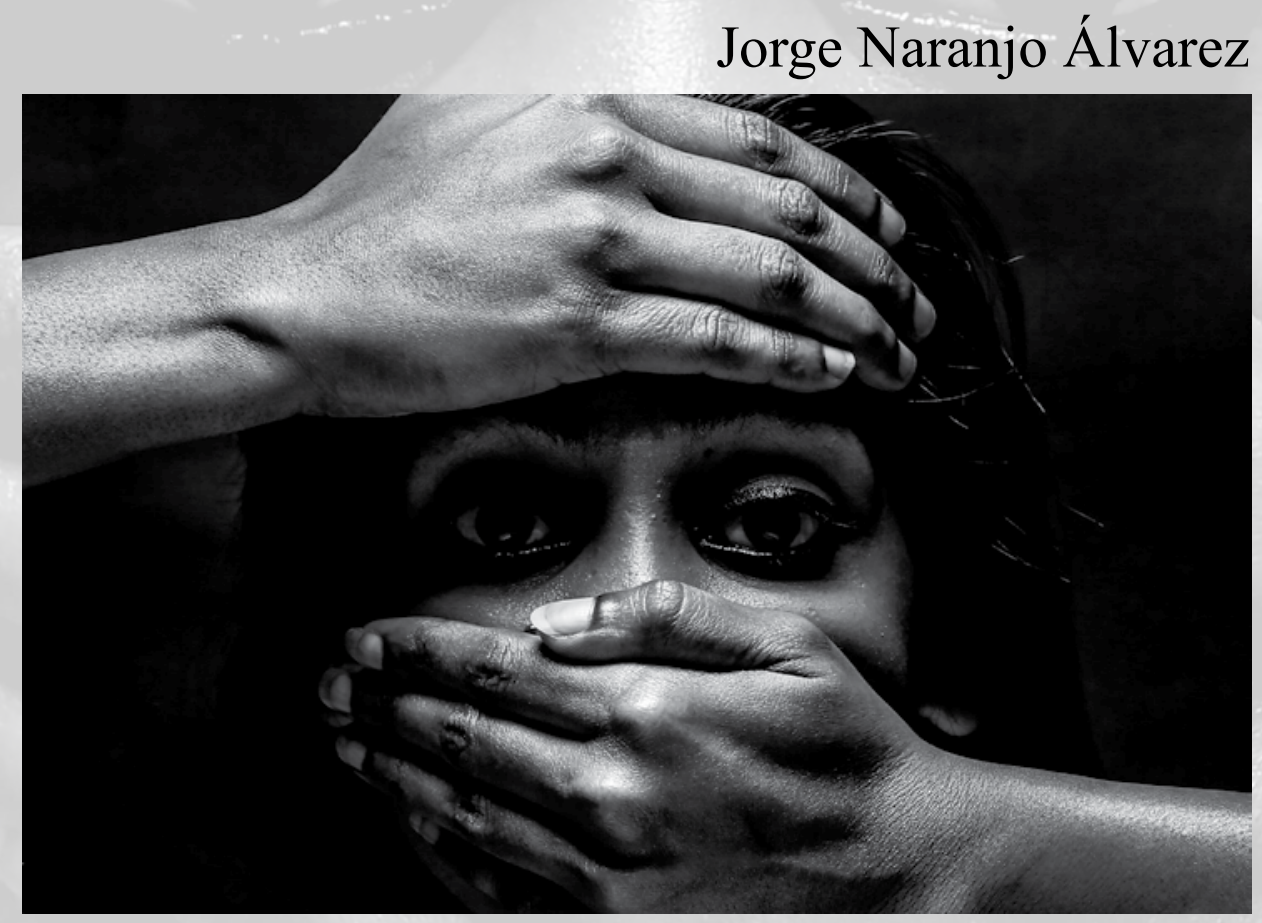





\title{
LA VIOLENCIA SEXUAL A LA LUZ DE LA LEY DE JUSTICIA Y PAZ: CONCEPTUALIZACIÓN Y ELEMENTOS PARA SU ESTUDIO*
}

\author{
Jorge Naranjo Álvarez \\ UNIVERSIDAD SANTO TOMÁS
}

\section{Resumen}

El artículo aborda el fenómeno de violencia sexual en el marco de la aplicación de la Ley 975 de 2005, llamada Ley de justicia y paz, y las reformas relacionadas. Se examinan sus disposiciones a la luz de los documentos más relevantes del derecho internacional humanitario y normativa nacional sobre la protección y la garantía de los derechos de las mujeres, para establecer los mecanismos enfocados a la obtención de verdad, justicia y reparación de las víctimas de violencia sexual. Más adelante se determinan los obstáculos que impiden el acceso a la justicia y la reparación de esta categoría especial de víctimas; en las conclusiones se proponen algunas alternativas para superarlos.

Palabras clave: violencia sexual, víctimas, justicia y paz.

El autor: docente e investigador de la Facultad de Derecho de la Universidad Santo Tomás sede Bogotá. Correo electrónico: jorgenaranjo@usantotomas.edu.co; jornaranjo99@hotmail.com

Recibido: 10 de febrero de 2021; evaluado: 15 de marzo de 2021; aceptado: 9 de abril de 2021.

El presente manuscrito es producto del proyecto de investigación "Debates contemporáneos en la administración de justicia penal en los albores del posconflicto colombiano", elaborado en la Facultad de Derecho de la Universidad Santo Tomás (Bogotá). 


\title{
SEXUAL VIOLENCE IN THE LIGHT OF THE LAW OF JUSTICE AND PEACE: CONCEPTUALIZATION AND ELEMENTS FOR ITS STUDY
}

\author{
Jorge Naranjo Álvarez \\ UNIVERSIDAD SANTo TOMÁS
}

\begin{abstract}
The article addresses the phenomenon of sexual violence within the framework of the application of Law 975 of 2005, known as Justice and Peace Law and related reforms. Its provisions are examined in the light of the most relevant documents of the international humanitarian law and national regulations on the protection and guarantee of women's rights, in order to establish the mechanisms focused on obtaining truth, justice and reparation for victims of sexual violence. Subsequently, the obstacles that impede access to justice and reparation for this special category of victims are identified. In the conclusions, some alternatives to overcome them are proposed.
\end{abstract}

Keywords: sexual violence, victims, justice and peace.

The author: Professor and researcher at the Faculty of Law of Universidad Santo Tomás, Bogotá, Colombia. E-mail: jorgenaranjo@usantotomas.edu.co; jornaranjo99@hotmail.com

Received: February 10, 2021; evaluated: March 15, 2021; accepted: April 9, 2021. 


\title{
A VIOLÊNCIA SEXUAL À LUZ DA LEI DE JUSTIÇA E PAZ: \\ CONCEITUAÇÃO E ELEMENTOS PARA SEU ESTUDO
}

\author{
Jorge Naranjo Álvarez \\ UNIVERSIDAD SANTO TOMÁs
}

\section{Resumo}

Neste artigo, aborda-se o fenômeno de violência sexual no âmbito da aplicação da Lei 975 de 2005, chamada "Lei de justiça e paz", e das reformas relacionadas. São examinadas suas disposições à luz de documentos mais relevantes do direito internacional humanitário e da legislação nacional sobre a proteção e a garantia dos direitos das mulheres, para estabelecer os mecanismos focados na obtenção da verdade, da justiça e da reparação das vítimas de violência sexual. Mais adiante, são determinados os obstáculos que impedem o acesso à justiça e à reparação dessa categoria especial de vítimas. Nas conclusões, são propostas algumas alternativas para superá-los.

Palavras-chave: violência sexual, vítimas, justiça e paz.

O autor: docente e pesquisador da Faculdade de Direito da Universidad Santo Tomás, sede Bogotá, Colômbia. Correio eletrônico: jorgenaranjo@usantotomas.edu.co; jornaranjo99@hotmail.com

Recebido: 10 de fevereiro de 2021; avaliado: 15 de março de 2021; aceito: 9 de abril de 2021. 


\section{Introducción}

Colombia ha suscrito varios pactos y tratados internacionales en el tema de defensa y protección de los derechos de la mujer, instrumentos que se integran al marco jurídico interno para fortalecer el bloque de constitucionalidad.

No obstante, entre los estándares del derecho internacional, las conceptualizaciones sobre la violencia sexual en el conflicto armado no internacional o guerra civil y su utilización como arma de guerra presentan ambivalencia y confusión, que se evidencian en las normas de derecho interno.

La reflexión de este artículo se desarrolla en torno al recorrido por la normativa más relevante sobre la violencia sexual en el marco del conflicto colombiano, con especial referencia a la aplicación de uno de los instrumentos normativos más notables en el proceso de negociación entre el Estado y el paramilitarismo, que favoreció el reconocimiento de este tipo de víctimas: la Ley 975 de 2005, denominada Ley de justicia y paz. Se precisan los mecanismos enfocados a esclarecer los hechos y obtener verdad, justicia y reparación para las víctimas de estas violencias. ${ }^{1}$

Para dichos fines, el documento emplea un diseño metodológico descriptivo, con enfoque cualitativo concentrado en la revisión de documentos, instrumentos e informes oficiales referentes al tema. El estudio se divide en dos apartados: en primer lugar, un acercamiento al delito de violencia sexual en el marco del conflicto a la luz de los instrumentos internacionales más relevantes; en segundo lugar, se analizan los obstáculos y algunas alternativas para el abordaje de estos eventos por la Ley 975 de 2005 de justicia y paz y las reformas normativas relacionadas.

\footnotetext{
"Víctima es la persona que individual o colectivamente haya sufrido daños directos tales como lesiones transitorias o permanentes que ocasionen algún tipo de discapacidad física, psíquica y/o sensorial (visual y/o auditiva), sufrimiento emocional, pérdida financiera o menoscabo de sus derechos fundamentales. Los daños deberán ser consecuencia de acciones que hayan transgredido la legislación penal, realizadas por grupos armados organizados al margen de la ley. También se tendrá por víctima al cónyuge, compañero o compañera permanente, y familiar en primer grado de consanguinidad, primero civil de la víctima directa, cuando a esta se le hubiere dado muerte o estuviere desaparecida. La condición de víctima se adquiere con independencia de que se identifique, aprehenda, procese o condene al autor de la conducta punible y sin consideración a la relación familiar existente entre el autor y la víctima". Colombia, Congreso de la República, Ley 975 de 2005, "Por la cual se dictan disposiciones para la reincorporación de miembros de grupos armados organizados al margen de la ley, que contribuyan de manera efectiva a la consecución de la paz nacional y se dictan otras disposiciones para acuerdos humanitarios" (Bogotá: Diario Oficial núm. 45980,25 de julio de 2005), art. 5.
} 


\section{La violencia sexual en el derecho internacional: hacia la precisión del concepto}

Varios son los documentos e instrumentos que contemplan la violencia sexual como uno de los delitos más execrables; no obstante, resulta complejo establecer una definición unívoca de violencia sexual que se ajuste a los parámetros internacionales. ${ }^{2}$

El Sistema Universal de Derechos Humanos (en adelante, SUDH) ha considerado la violencia contra la mujer, específicamente la violencia sexual, como una forma de discriminación basada en el sexo. Encontramos múltiples documentos en los que se intenta establecer mayores precisiones del concepto, como el Pacto internacional de derechos civiles y políticos (PIDCP lit. c.), la Convención sobre los derechos del niño (art. 2.1., lit. d) y la Convención internacional sobre la protección de los derechos de todos los trabajadores migratorios y sus Familias (art. 7).

Sobresale también el Estatuto de Roma, de la Corte Penal Internacional (CPI), que incorporó reglas sobre el manejo de la prueba, y dos convenciones que promueven la no discriminación y el ejercicio de cualquier tipo de violencia: a) Eliminación de todas las formas de discriminación contra la mujer (Cedaw), y b) la Convención interamericana para prevenir, sancionar y erradicar la violencia contra la mujer (Convención Belém do Pará), instrumentos que analizaremos a continuación:

En primer lugar, la Convención sobre la eliminación de todas las formas de discriminación contra la mujer (Cedaw), ratificada por Colombia en enero de 1982, establece una clara delimitación del fenómeno en estudio.

De acuerdo con Guarnizo, allí define la discriminación contra la mujer como:

[...] toda distinción, exclusión o restricción basada en el sexo que tenga por objeto o por resultado menoscabar o anular el reconocimiento, goce o ejercicio por la mujer independientemente de su estado civil, sobre la base de la igualdad del hombre y la mujer, de los derechos humanos y las libertades

Joaquín Gallego, "Paradoja y complejidad de los derechos humanos en la sociedad moderna. Sentido y comunicación", IUSTA 1, núm. 40 (enero-junio 2014): 5, https://revistas.usantotomas.edu.co/index.php/ iusta/article/view/2453 (acceso enero 5, 2018). 
fundamentales en las esferas política, económica, social, cultural y civil o en cualquier otra esfera. ${ }^{3}$

La Organización de las Naciones Unidas (ONU), por su parte, ha establecido una relación directa entre las violaciones a los derechos de las mujeres y las obligaciones del Estado para conjurarlas y propone a los Estados desarrollar acciones preventivas que protejan a la mujer contra la violencia, así como sanciones penales, recursos civiles e indemnizaciones. El Cedaw, en su Recomendación 19, sostuvo:

En virtud del derecho internacional y de pactos específicos de derechos humanos, los Estados también pueden ser responsables de actos privados si no adoptan medidas con la diligencia debida para impedir la violación de los derechos o para investigar y castigar los actos de violencia e indemnizar a las víctimas (cursivas propias). ${ }^{4}$

Otro instrumento internacional suscrito por Colombia, relevante para nuestro objeto de estudio, es la Declaración sobre la eliminación de la violencia contra la mujer (1993), que establece una definición semejante y se pronuncia sobre el deber del Estado para prevenir, investigar y sancionar este tipo de violencia, ya sea perpetrado por el Estado o por civiles, es decir, el deber de brindar mecanismos que favorezcan la rehabilitación y la reparación integral de estas víctimas:

[...] por "violencia contra la mujer" se entiende todo acto de violencia basado en la pertenencia al sexo femenino que tenga o pueda tener como resultado un daño o sufrimiento físico, sexual o sicológico para la mujer, así como las amenazas de tales actos, la coacción o la privación arbitraria de la libertad, tanto si se producen en la vida pública como en la vida privada. ${ }^{5}$

En este mismo sentido se erigen la Declaración y el Plan de acción de Beijing, promulgados durante la celebración de la Cuarta Conferencia sobre la Mujer (1995), en la que se reconoce como tema de preocupación "la mujer en los conflictos armados" y se fijan acciones concretas de los Estados para la adopción de medidas

3 Mesa de Seguimiento al Auto 092 de la Corte Constitucional, Acceso a la justicia para mujeres víctimas de violencia sexual. Cuarto informe de seguimiento al Auto 092 de la Corte Constitucional (Bogotá: Anthropos, 2011), art. 1.

4 Convención sobre la eliminación de todas las formas de discriminación contra la mujer [Cedaw], Recomendación general № 19 (Nueva York, 29 de marzo de 1992), párr. 9.

5 Organización de las Naciones Unidas [ONU], Declaración sobre la eliminación de la violencia contra la mujer (Nueva York, 20 de diciembre de 1993), art. 1. 
adecuadas de intervención psicosocial, con el objetivo de eliminar y prevenir de cualquier tipo de violencia, así como establecer sistemas de información adecuados. Admite que:

Se cometen graves violaciones de los derechos humanos de las mujeres, en particular en épocas de conflicto armado, que incluyen el asesinato, la tortura, las violaciones sistemáticas, embarazos forzados y abortos forzados, en particular en lugares donde se aplican políticas de depuración étnica. Así las cosas, el mantenimiento de la paz y la seguridad a nivel mundial, regional y local, junto con la prevención de las políticas de agresión y de depuración étnica y la solución de los conflictos armados, tienen importancia decisiva para la protección de los derechos humanos de las mujeres y las niñas, así como para la eliminación de todas las formas de violencia contra ellas y de su utilización como arma de guerra. ${ }^{6}$

Este reconocimiento está presente en el Protocolo facultativo de la Convención sobre la eliminación de todas las formas de discriminación contra la mujer (A/54/4 de 1999), ${ }^{7}$ que crea un esquema de formulación de denuncias por aquellos que aleguen ser víctimas de una violación por un Estado parte de cualquiera de los derechos enunciados en el instrumento, que incluyen la imposición de medidas de protección provisional mientras dure la investigación correspondiente. ${ }^{8}$

Según Guarnizo, ${ }^{9}$ estas obligaciones en relación con la violencia sexual en el conflicto son complementadas por el Consejo de Seguridad de las Naciones Unidas por medio de varias resoluciones:

La Resolución 1325 reconoce:

La necesidad de aplicar plenamente las disposiciones del derecho internacional humanitario y del relativo a los derechos humanos que protejan los derechos de las mujeres y las niñas durante los conflictos y después de ellos [e] insta

6 Organización de las Naciones Unidas [ONU], Declaración y plataforma de acción de Beijing (Beijing, 15 de septiembre de 1995), 11.

7 Organización de las Naciones Unidas [ONU], Protocolo facultativo de la Convención sobre eliminación de todas las formas de discriminación contra la mujer (Nueva York, 6 de octubre de 1999), art. 4.

8 María Quiroz, "Un acercamiento a las 'oposiciones paradigmáticas' entre neoconstitucionalismo y positivismo jurídico", IUSTA 1, núm. 41 (junio-septiembre 2014): 8, https://revistas.usantotomas.edu.co/index.php/ iusta/article/view/2470 (acceso enero 15, 2018).

9 Mesa de Seguimiento al Auto 092 de la Corte Constitucional, Acceso, 12. 
a todas las partes en un conflicto armado a que adopten medidas especiales para proteger a las mujeres y las niñas de la violencia por razón de género particularmente la violación y otras formas de abusos sexuales (cursivas propias). ${ }^{10}$

Por su parte, la Resolución 1820 conmina a los Estados a efectuar las labores de enjuiciamiento y garantía de las víctimas de actos de violencia sexual y hace un llamado a garantizar, en pie de igualdad, a las niñas y mujeres:

[... la protección de la ley y del acceso a la justicia, y subraya la importancia de poner fin a la impunidad por esos actos como parte de un enfoque amplio para alcanzar la paz sostenible, la justicia, la verdad y la reconciliación nacional. ${ }^{11}$

Las Resoluciones 1820 de 2008 y 1888 de $2009^{12}$ del Consejo de Seguridad establecen la priorización del enjuiciamiento de las agresiones contra la integridad sexual, con base en el respeto por el principio de responsabilidad de mando. Indican la necesidad de crear un sistema unificado e integrado de enjuiciamiento derivado de un plan de acción para abordar este tipo de violencia en el seno de la Secretaría General del organismo.

La preocupación por la sistematicidad y generalización de los actos de violencia contra las mujeres y los niños durante o con ocasión del conflicto se refleja también en la Resolución $1960^{13}$ del mismo organismo, que muestra la intranquilidad frente a la continuidad de estos actos de violencia, fenómeno que se manifiesta de manera continua, brutal, sistemática y generalizada.

De igual manera, en el Sistema Interamericano de Derechos Humanos encontramos varios documentos que contemplan la importancia de eliminar violencias, por ejemplo, la Convención interamericana para prevenir, sancionar y erradicar la violencia contra la mujer — llamada también Convención de Belém do Pará- de 1994, que dispone: el derecho de toda mujer a "una vida libre de violencia tanto en

10 Organización de las Naciones Unidas [ONU], Consejo de Seguridad, Resolución 1325 de 2020 (Nueva York, 31 de octubre de 2020), Preámbulo.

11 Organización de las Naciones Unidas [ONU], Consejo de Seguridad, Resolución 1820 de 2008 (Nueva York, 19 de junio de 2008), 12.

12 Organización de las Naciones Unidas [ONU], Consejo de Seguridad, Resolución 1888 de 2009 (Nueva York, 30 de septiembre de 2009), 4.

13 Organización de las Naciones Unidas [ONU], Consejo de Seguridad, Resolución 1960 de 2010 (Nueva York, 16 de diciembre de 2010), 1. 
el ámbito público como en el privado", ${ }^{14}$ el cual incluye el derecho de toda mujer a ser libre de discriminación. ${ }^{15}$

Para el instrumento internacional, la violencia contra la mujer se configura con cualquier acción o conducta basada en su género que cause muerte, daño o sufrimiento físico, sexual o psicológico a la mujer tanto en el ámbito público como en el privado. Impone a los Estados la obligación de:

c. incluir en la legislación interna normas penales, civiles y administrativas, así como las de otra naturaleza que sean necesarias para prevenir, sancionar y erradicar la violencia contra la mujer y adoptar las medidas administrativas apropiadas que sean del caso; d. adoptar medidas jurídicas para conminar al agresor a abstenerse de hostigar, intimidar, amenazar, dañar o poner en peligro la vida de la mujer de cualquier forma que atente contra su integridad o perjudique su propiedad; e. tomar todas las medidas apropiadas, incluyendo medidas de tipo legislativo, para modificar o abolir leyes y reglamentos vigentes, o para modificar prácticas jurídicas o consuetudinarias que respalden la persistencia o la tolerancia de la violencia contra la mujer. ${ }^{16}$

En materia de administración de justicia, el instrumento ${ }^{17}$ obliga a los Estados parte a instituir procedimientos jurisdiccionales que garanticen medidas de protección eficaces para las víctimas de violencia, incluso aquellos concernientes a la obtención de un juicio justo, la reparación y la garantía de no repetición. Como vemos, este es uno de los instrumentos internacionales más explícitos en torno a lo que la Corte IDH reconoce como el deber de "debida diligencia de un Estado". ${ }^{18}$

Por su parte, para la Corte Constitucional colombiana, la violencia sexual es definida como:

Una práctica habitual, extendida, sistemática e invisible en el contexto del conflicto armado colombiano, así como lo son la explotación y el abuso sexuales,

14 Organización de los Estados Americanos [OEA], Convención interamericana para prevenir, sancionar y erradicar la violencia contra la mujer "Convención de Belém do Parâ" (Belém do Pará, 9 de junio de 1994), art. 3.

15 OEA, Convención de Belém do Pará, art. 16.

16 OEA, Convención de Belém do Pará, art. 7, lit. a y b.

17 OEA, Convención de Belém do Pará, art. 7, lit. f, g, h.

18 Corte Interamericana de Derechos Humanos, Sentencia del 15 de junio de 2005, Caso de la Comunidad Moiwana Vs. Suriname, serie C, 124. 
por parte de todos los grupos armados ilegales enfrentados, y en algunos casos aislados, por parte de agentes individuales de la Fuerza Pública. ${ }^{19}$

El Estatuto de Roma, que crea la Corte Penal Internacional en 1998, delimita las conductas que pueden considerarse violencia sexual en el marco del conflicto armado no internacional o de guerra civil. Precisa que pueden ubicarse en tres categorías, recogidas en la jurisprudencia del Tribunal Penal Internacional para la ex-Yugoslavia y el Tribunal Penal Internacional para Ruanda: a) crímenes de lesa humanidad: si forman parte de un ataque amplio y sistemático contra una población; b) crímenes de guerra: si el acto de violencia se comete en conflictos armados internacionales y no internacionales, y c) genocidio: si se emplea como estrategia de exterminio y persecución a un grupo o una etnia particular.

De acuerdo con Portal, en el Estatuto se contemplan como crímenes de violencia sexual los siguientes:

- Violación sexual:

[...] la invasión del cuerpo de una persona mediante una conducta que haya ocasionado la penetración — por insignificante que fuera — de cualquier parte del cuerpo de la víctima o del autor con un órgano sexual o del orificio anal o vaginal de la víctima con un objeto u otra parte del cuerpo. Esta invasión deberá producirse por la fuerza o mediante la amenaza de la fuerza [...].

- Esclavitud sexual: entendido como que el autor haya ejercido uno de los atributos del derecho de propiedad sobre una o más víctimas, como comprarlas, venderlas, prestarlas, darlas en trueque o todas ellas; o les haya impuesto algún tipo similar de privación de la libertad con el fin que éstas realicen actos de naturaleza sexual.

- Prostitución forzada: consiste en obligar a una o más personas a realizar uno o más actos de naturaleza sexual por la fuerza, amenaza del uso de la fuerza o la coacción, como la causada por el temor a la violencia, [...] con el fin de obtener ventajas económicas o de otro tipo a cambio de dichos actos.

19 Colombia, Corte Constitucional, Auto 092 de 14 de abril de 2008, M. P. Manuel José Cepeda Espinosa. 
- Embarazo forzado: es el confinamiento de una o más mujeres que fueron embarazadas por la fuerza, con el fin de cambiar la composición étnica de una población o cualquier otro fin contrario al derecho internacional.

- Esterilización forzada: consiste en privar a una o más personas, sin su libre consentimiento, de su capacidad de reproducción biológica, y sin justificación alguna en un tratamiento médico o clínico.

- Otros actos de violencia sexual de gravedad comparable: estos otros actos deben consistir en un acto de naturaleza sexual. Al mismo tiempo, la víctima debe haber realizado este acto por la fuerza, amenaza de la fuerza o coacción, como la causada por el temor a la violencia, la intimidación, la detención, la opresión psicológica o el abuso de poder contra ella u otra persona o aprovechando un entorno de coacción o la incapacidad de esa o esas personas de dar su libre consentimiento. ${ }^{20}$

En los conflictos armados también se pueden presentar otros tipos violencia sexual, por ejemplo:

1. Unión forzada: son aquellos actos en los que se obliga a una o más personas a contraer matrimonio o a convivir con otra persona, de manera que se generan actos de naturaleza sexual al interior de esta unión forzada.

2. Aborto forzado: se obliga a una mujer a abortar mediante el uso de la fuerza, la amenaza o cualquier forma de coacción.

3. Mutilación genital: en el caso de las mujeres, se refiere a la extirpación parcial total de los órganos genitales femeninos. Su forma más severa es la infibulación, también conocida como circuncisión faraónica. El procedimiento incluye: a) la clitoridectomía (por la que se extirpa total o parcialmente el clítoris); b) la escisión (extirpación de la totalidad o de parte de los labios menores), y c) la ablación de los labios mayores. ${ }^{21}$

20 Diana Portal, Violencia sexual en conflictos armados: evolución del derecho y el acceso a la justicia de las mujeres (Lima: Demus, Estudio para la defensa de los derechos de la mujer, 2008), 18.

21 Portal, Violencia, 19. 
El Estatuto, además, incorpora reglas sobre el procedimiento y otras sobre el peritaje de las pruebas en la violencia sexual, para lo cual establece la Regla 70 de procedimiento y prueba:

a. El consentimiento no podrá inferirse de ninguna palabra o conducta de la víctima cuando la fuerza, la amenaza de la fuerza, la coacción o el aprovechamiento de un entorno coercitivo haya disminuido su capacidad para dar un consentimiento voluntario y libre.

b. El consentimiento no podrá inferirse de ninguna palabra o conducta de la víctima cuando esta sea incapaz de dar un consentimiento libre.

c. El consentimiento no podrá inferirse del silencio o de la falta de resistencia de la víctima a la supuesta violencia sexual.

d. La credibilidad, la honorabilidad o la disponibilidad sexual de la víctima o de un testigo no podrán inferirse de la naturaleza sexual del comportamiento anterior o posterior de la víctima o de un testigo. ${ }^{22}$

\section{Violencia sexual en Colombia: conflicto armado, justicia y paz desde la normativa nacional}

Colombia ha sido uno de los territorios donde se presentan, de manera sistemática y generalizada, varias manifestaciones de violencia, incluida la violencia sexual selectiva e individual como una estrategia de guerra para atemorizar a la comunidad.

Estos delitos recaen especialmente en las mujeres, porque, según Chaparro:

(a) son las principales sobrevivientes del conflicto y por tanto las principales denunciantes; (b) han sido víctimas directas de violencias relacionadas con su condición de género, que exige de las autoridades una mayor comprensión de los patrones socioculturales que subyacen a esas violencias; (c) el conflicto las ha golpeado de manera diferencial y agudizada por su condición de género, que las expone a riesgos particulares y específicos. [... . requieren de medidas de protección que tengan en cuenta su situación y sus necesidades

22 Corte Penal Internacional, Reglas de procedimiento y prueba (Nueva York, Corte Penal Internacional, 2013), 23. 
particulares y, especialmente, que consideren las razones que han provocado su victimización y consecuencias. ${ }^{23}$

Esta aseveración se hace más contundente al revisar los reportes del sistema integrado de información sobre violencias de género que, al 30 de mayo de 2020, refiere 32347 casos de violencia sexual, de los cuales el 92,1 \% se concentra en la población femenina, tal como puede inferirse de las cifras oficiales (Figura 1).

Tabla 1. Violencia sexual según género

\begin{tabular}{|l|c|c|}
\hline & Mujer & Hombre \\
\hline Primera infancia & 0,2 & 0,17 \\
\hline Infancia & 0,5 & 0,51 \\
\hline Adolescencia & 1,47 & 1,15 \\
\hline Persona mayor & 5,91 & 0,51 \\
\hline Juventud & 13,34 & 2,01 \\
\hline Adultez & 70,68 & 3,54 \\
\hline Total & 92,1 & 7,89 \\
\hline
\end{tabular}

Fuente: elaboración propia con datos tomados del Sistema Integrado de Información de Violencias de Género. "Indicadores de violencia sexual". https://cutt.ly/Qn9fj4W (acceso noviembre 5, 2020).

23 Liliana Chaparro M., "Ley de Justicia y Paz. Se perpetúa la impunidad de los crímenes sexuales y de género cometidos contra las mujeres" en iJusticia desigual? Género y derechos de las víctimas en Colombia, coord. por Margarita Bueso (Bogotá: Fondo de las Naciones Unidas para la mujer, 2019), 92 
Figura 1. Violencia sexual según género

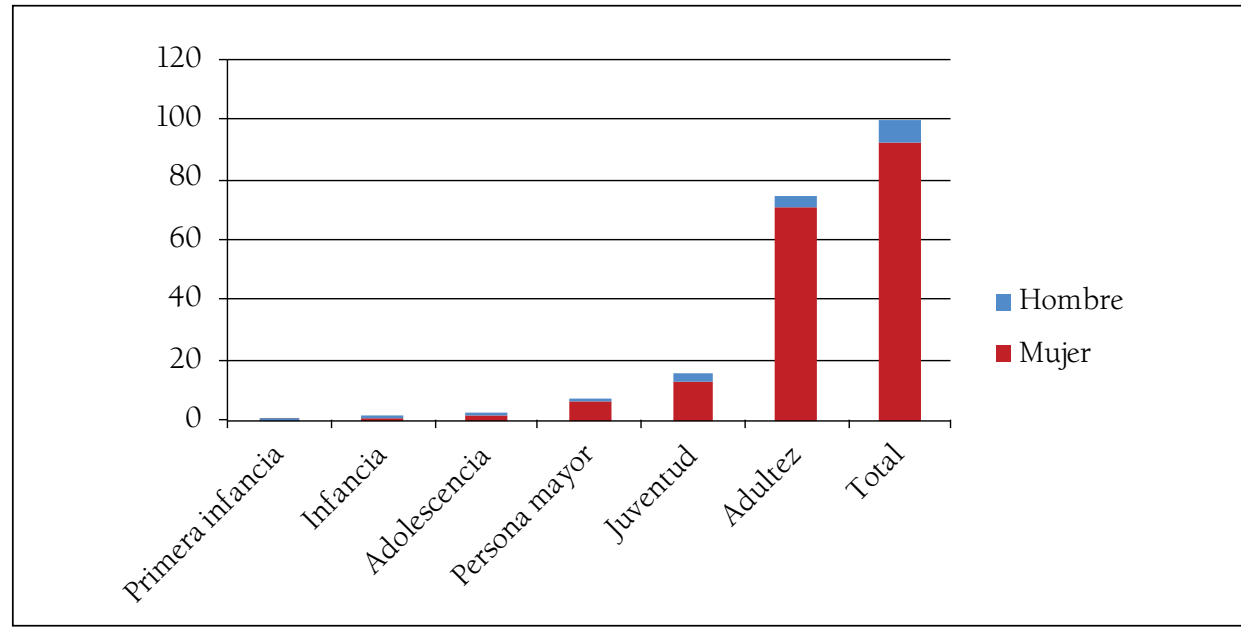

Fuente: elaboración propia con datos tomados del Sistema Integrado de Información de Violencias de Género. "Indicadores de violencia sexual". https://cutt.ly/Qn9fj4W (acceso noviembre 5, 2020).

Un resultado similar ya había arrojado el informe Mujeres en conflicto: violencia sexual y paramilitarismo, elaborado por la Corporación Sisma Mujer en el año 2009. Allí se relata que, en 44990 relatos de violencia paramilitar registrados entre el 1 de julio de 1996 y el 31 de diciembre de $2006,{ }^{24}$ se observa que la violencia sexual sobre el cuerpo de las mujeres ha sido predominante y con múltiples manifestaciones:

Así, a partir del análisis de los relatos de las víctimas de violencia sexual en el conflicto armado se identificaron cinco modalidades utilizadas por los paramilitares para justificar esta conducta como estrategia de guerra (Figura 2):

1. El $6,19 \%$ de las agresiones sexuales fue sufrido por mujeres señaladas de sostener vínculos reales o presuntos con la guerrilla, es decir, ser simpatizantes, tener una relación emocional o ser informantes.

2. El 29,9\% de los testimonios se produjo en el contexto de masacres o de invasiones paramilitares a gran escala.

3. El $26,80 \%$ de los relatos, al parecer, se hizo bajo la selectividad previa e individualización de la víctima. Sobresale el 11 \% de estas mujeres con una

24 Corporación Sisma Mujer, Mujeres en conflicto: violencia sexual y paramilitarismo (Bogotá: Litoxpress, 2009), 17. 
identidad representativa, el $2 \%$ sufrió la conducta por tener identidad hereditaria y el $12 \%$ por ser considerada con identidad ignominiosa.

4. En el 6,19\% de los casos, la agresión sexual fue consecuencia de la presencia y permanencia consolidada de los grupos paramilitares en la zona que ejercían control social del territorio y se manifestó mediante esclavitud sexual y prostitución forzada.

5. Por último, en el 30,93 \% de las evidencias se observó una práctica indiscriminada, disgregada y generalizada en todo el contexto nacional.

Figura 2. Reporte modalidades de violencia sexual ejercida por los grupos paramilitares

\begin{tabular}{|c|c|}
\hline & Indiscriminada, desagregada \\
& y propagada \\
& Incursiones paramilitares a \\
& gran escala \\
& Selectiva \\
& En zonas ocupadas por \\
& paramilitares \\
& Contra señaladas como \\
simpatizantes & \\
& \\
\hline
\end{tabular}

Fuente: elaboración propia adaptada de datos de Corporación Sisma Mujer, Mujeres en conflicto: violencia sexual y paramilitarismo (Bogotá: Litoxpress, 2009), 38.

Tabla 2. Reporte modalidades de violencia sexual ejercida por los grupos paramilitares

\begin{tabular}{|l|c|c|}
\hline \multicolumn{1}{|c|}{ Modalidad } & Casos reportados & Porcentaje \\
\hline Indiscriminada, desagregada y propagada & 30 & 30,93 \\
\hline Incursiones paramilitares a gran escala & 29 & 29,9 \\
\hline Selectiva & 26 & 26.80 \\
\hline En zonas ocupadas por paramilitares & 11 & 6,19 \\
\hline Contra señaladas como simpatizantes & 6 & 6,19 \\
\hline Total & 102 & 100 \\
\hline
\end{tabular}

Fuente: elaboración propia adaptada de datos de Corporación Sisma Mujer, Mujeres en conflicto: violencia sexual y paramilitarismo (Bogotá: Litoxpress, 2009), 39. 
$\mathrm{Al}$ analizar los relatos sobre violencia sexual que participaron en su investigación, se menciona:

En cuanto a los objetivos que definieron las razones de las masacres acompañadas de violencia sexual por parte de los grupos paramilitares, se identificaron dos estrategias encaminadas a la expansión del poder territorial. Por un lado, se buscó el exterminio de una población, bien sea mediante su desaparición total a través de la ejecución de un alto número de víctimas, o la generación de altos grados de desplazamiento. En segundo lugar, en razón a la forma como se ejerció la violencia sexual, se buscó la subordinación y desarticulación de las redes sociales, y se constituyó en un mecanismo para intimidar a la población como estrategia de guerra. ${ }^{25}$

En este desalentador contexto, la Ley de Justicia y Paz pretendió reflejar algunas de las obligaciones internacionales asumidas por Colombia para la defensa y la garantía de los derechos de las víctimas desde una perspectiva de género, al condenar los actos de la violencia sexual y puntualizar en el derecho de la mujer a la intimidad y su protección, así como la excepción a la rebaja de penas.

Entre los elementos más relevantes de la Ley encontramos:

1. Reconocimiento de las necesidades de las mujeres: las autoridades deben reconocer las conductas punibles que atentan contra el desarrollo de su sexualidad; ${ }^{26}$ la Procuraduría es el ente encargado de velar por este cumplimiento. Se requiere una política que, en la práctica, responda a las necesidades de la mujer y la empodere para exigirle al Estado.

2. Ejercicio del derecho a la intimidad: las víctimas tienen derecho a acceder a los archivos. El Tribunal Superior del Distrito Judicial puede autorizar la toma del testimonio, mediante un audio/video que facilite la confrontación y contradicción entre las partes, en especial para la protección de víctimas de agresión sexual o de niños, niñas, adolescentes o el testigo ${ }^{27}$ y evitar la revictimización.

25 Corporación Sisma Mujer, Mujeres, 55-56.

26 Colombia, Presidencia de la República, Decreto 4760 de 2005, "Por el cual se reglamenta parcialmente la Ley 975 de 2005" (Bogotá: Diario Oficial núm. 46 137, 30 de diciembre de 2005), art. 11

27 Colombia, Congreso de la República, Ley 975 de 2005, art. 39. 
3. Acceso a medidas de protección: se requería que las normas mencionadas se reglamentaran; por eso en 2007, mediante sentencia judicial; ${ }^{28}$ el Tribunal Administrativo de Cundinamarca ordenó en esta ley la creación de un programa de protección a víctimas y testigos, el cual se hizo realidad con el Decreto 3570 de 2007 y dispuso la importancia de capacitar a la policía judicial en enfoque de género, con el fin de lograr estrategias de protección particulares por su condición.

A pesar de los reconocimientos, la Ley 975 de $2005^{29}$ presentaba en su primera versión varias falencias, que se concentraban en tres tipos de vacíos:

\subsection{Garantías para la denuncia}

Aunque el Estado colombiano había establecido algunas disposiciones procesales sobre los derechos de las víctimas, para favorecer su acceso a la justicia, estas acciones de intervención preventivas y jurídicas no habían sido suficientes, porque la víctima no denunciaba por temor; existían delitos no tipificados como la desnudez, la esterilización y el aborto forzados y otras formas de violencia sexual; si las pruebas no eran contundentes, el autor de los hechos quedaba impune, fenómeno que contrariaba lo precisado por el régimen probatorio.

Tanto en las normas como en la jurisprudencia se ha señalado que no es necesario corroborar el testimonio de las víctimas de violencia sexual, que las pruebas que hagan referencia al comportamiento sexual de la víctima deben ser inadmisibles en el proceso y que la falta de precisión en el relato de la víctima sobre hechos, detalles de acontecimientos y fechas no puede ser usada para desestimar su testimonio. ${ }^{30}$

Ejemplo de dichos exabruptos constituye el relato de José Castaño en la revista Semana, años después de la Ley 975 de 2005 y después de crearse la ilusión de un verdadero proceso de paz y cesación de hostilidades, cuando la violencia sexual era una extensión del fusil: 
María José, una mujer de 59 años, cuyo hijo era del Ejército contrainsurgente en el Caguán, antigua zona de distensión durante el gobierno de Pastrana; la cual fue violada por un guerrillero de las FARC.

Mientras la violaba, el guerrillero le gritaba insultos y después la amenazaba.

Cuando todo terminó ella se fue al patio y buscó el limonero, a un lado del baño. "Corté unos limones, los partí y me los pasé por todo el cuerpo, las piernas, el pecho, los brazos, la boca", dice María, y debe contenerse para no llorar $[\ldots]$.

Cuando su hija la llevó a Medicina Legal para formalizar la denuncia, lo único que encontraron los peritos fueron quemaduras por el ácido cítrico del limón. ${ }^{31}$

La falta de evidencias físicas, como en el caso relatado, es frecuente, ya que las víctimas, en un afán de limpiar la suciedad e impureza que experimentan, borran de su cuerpo todo rastro de semen y saliva del agresor, pero, más allá de esto, se encuentran los recuerdos y las sensaciones que no se pueden lavar y difícilmente se pueden borrar, aun con un proceso de intervención psicológica. La terapia ayuda a disminuir el impacto de la experiencia vivida mediante la expresión de la rabia, la frustración y la culpabilidad, lo cual ayuda a la víctima a continuar con su vida y enfrentar de una manera diferente lo ocurrido.

\subsection{Impunidad ante los hechos}

De acuerdo con la Mesa de Seguimiento al Auto 092, a septiembre de 2010,32 a pesar de la reasignación de casos a las unidades de la Fiscalía no se observaban avances en el estado procesal de los casos remitidos:

[...] solo cuatro casos $(2,1 \%)$ habían terminado en sentencia condenatoria; 14 casos (7,3\%) habían terminado en archivo, ya sea porque la Fiscalía se inhibió de abrir investigación (12 casos que representan el 6,3 \%) o fueron precluidos (2 casos, que representan el $1 \%$ ).

De los casos que aún se encontraban activos, 140, que representan el 73,3\% del total reportado por la Fiscalía, se encontraban en etapa de investigación

31 José Castaño, "Los abusos de la guerra", Semana, Sec. Conflicto armado, 6 agosto, 2010.

32 Mesa de Seguimiento al Auto 092 de la Corte Constitucional, Acceso, 37-38. 
sin que se hubiera vinculado al presunto autor; solo 17 casos $(8,9 \%)$ se encontraban en juicio, mientras que $16(8,4 \%)$ están en etapa de investigación con vinculación de un presunto autor. ${ }^{33}$

En el análisis de la gestión investigativa de las unidades de la Fiscalía, se observó que en 2009 se tomaron como base los 177 casos reportados, de los cuales 68 fueron asignados a la Unidad de Derechos Humanos y 109 a las unidades seccionales y, para 2010, con un total de 191 casos, 82 correspondieron a la Unidad de Derechos Humanos y 109 a las unidades seccionales.

Por su parte, respecto a la situación procesal de los casos investigados por las seccionales, se verificó que el reporte de 2009 era igual al presentado en 2010, lo que demostró la ausencia de gestión, mientras que en la Unidad de Derechos Humanos y Derecho Internacional Humanitario se veían algunos avances insuficientes.

La situación se tornó mucho más crítica si, se tiene en cuenta que, a septiembre de 2010, el 57 \% (109) de los casos reportados en el Auto, todavía se encontraba en Fiscalías seccionales.

Más adelante, junto con las cifras de impunidad halladas y con la información técnica recibida el día 10 de mayo de 2007 por los voceros de las mujeres desplazadas, la Corte y los magistrados que integraban la Sala Segunda de Revisión; en el Auto 092 basado en la Sentencia T-025 (2004), ${ }^{34}$ identificó 183 casos de presuntos crímenes sexuales cometidos durante o con ocasión del conflicto armado, los cuales fueron remitidos a la Fiscalía y Procuraduría en anexo reservado.

Al respecto, la Corte Constitucional expresa:

Es significativo que, hasta la fecha, no se hayan adoptado en el marco del proceso de la Ley de Justicia y Paz medidas para sancionar a los perpetradores de crímenes sexuales contra mujeres desplazadas. No existen tampoco mecanismos dentro del proceso de declaración y caracterización para detectar este tipo de situaciones. ${ }^{35}$

\footnotetext{
Mesa de Seguimiento al Auto 092 de la Corte Constitucional, Acceso, 37-38.

34 Providencia que declaró el Estado de cosas inconstitucional ante la desprotección y la falta de garantías en el ejercicio de los derechos de 600 mujeres afectadas por el desplazamiento forzado en el conflicto armado.

35 Colombia, Corte Constitucional, Auto 092 de 2008, M. P. Manuel Cepeda, Jaime Córdoba y Rodrigo Escobar, 64.
} 
La Corporación no era "la entidad judicial competente para realizar, desde el punto de vista penal, la determinación fáctica ni la valoración y calificación jurídica de estos eventos que se han relatado ante la Sala a través de diversos medios". ${ }^{36}$ Dada la importancia de los testimonios, por su carácter reiterado, coherente y consistente, decidió involucrar a las demás instancias competentes del Gobierno, entre ellas la Fiscalía General de la Nación, para que dispusieran las medidas a la mayor brevedad posible, con el fin de impactar la lentitud que hay en el proceso investigativo de los hechos y la dificultad para que las víctimas accedieran a la verdad, justicia y reparación.

A su vez, encargó a la Procuraduría General de la Nación para que vigilara el cumplimiento de estas disposiciones por parte del Estado. ${ }^{37}$

\subsection{Sistema de registro deficiente y poco confiable}

La Mesa de Seguimiento informaba: "No existe una base de datos unificada, confiable y consistente que dé cuenta de todas las investigaciones de violencia sexual que en el contexto del conflicto armado existen en el país". ${ }^{38}$ Además, observaba diferencias entre la información sobre los casos que tenían la Fiscalía y las entidades que formaban parte de la Mesa. Se consideró que la génesis de esta deficiencia en el proceso de sistematización distaba mucho más de un formato para registrar los hechos o de la falta de entrenamiento y rutina del proceso de entrevista por parte del personal que abordaba a las víctimas o de la utilización de un peritaje técnico, más que psicológico y antropológico, que permitiera caracterizar este delito.

\section{Luego de Justicia y paz: avances y retrocesos}

En Colombia ya se habían producido algunos progresos para abordar el fenómeno de violencia sexual, por ejemplo, mediante la Ley 906 de 2004, cuyo Artículo 11 reconocía como derechos de la víctima el respeto a su seguridad e intimidad, la reparación, a ser informada, la asistencia legal y un traductor; la Ley 360 de 1997, que en su Artículo 15 hacía referencia al derecho de la víctima a recibir tratamiento por trauma físico y emocional, y la prevención de enfermedades venéreas, así como a

Colombia, Corte Constitucional, Auto 092 de 2008.

37 Sonia Cortés, "Derechos humanos en las políticas de paz y posconflicto en Colombia", Vía Inveniendi et Iudicandi 11, núm. 1 (enero-junio 2016): 129-145, https://revistas.usantotomas.edu.co/index.php/viei/ article/view/2926 (acceso enero 3, 2018)

38 Corte Constitucional, Auto 092 de 2008, 69. 
acceder gratuitamente a la recopilación de evidencia médica legal o la ya analizada; la Ley 975 de 2005, que disponía medidas especiales de protección a la seguridad, la vida privada y la intimidad de las víctimas y testigos en sus Artículos 38, 39 y 58.

No obstante, ante el desalentador panorama de aumento de casos y los pocos avances de judicialización y con el objetivo de profundizar en lo ya alcanzado por la Ley 975 de 2005 y garantizar mecanismos idóneos de verdad justicia y reparación para las víctimas, se emitieron normas complementarias que, a su vez, emanan de varias decisiones judiciales.

La primera de ellas, la Ley 1257 de 2008, se pronuncia concretamente sobre medidas de sensibilización, prevención y sanción de las diferentes manifestaciones de este delito, pero, una vez más, no lee el fenómeno a la luz del conflicto armado y de las mujeres desplazadas por este. La norma define la violencia sexual como:

[...] cualquier acción u omisión, que le cause muerte, daño o sufrimiento físico, sexual, psicológico, económico o patrimonial por su condición de mujer, así como las amenazas de tales actos, la coacción o la privación arbitraria de la libertad, bien sea que se presente en el ámbito público o en el privado. ${ }^{39}$

Sin embargo, estas acciones preventivas y jurídicas aún eran insuficientes frente a la presentación de los hechos en diferentes contextos, porque la mujer no denunciaba, tenía miedo; además, existían delitos que no estaban tipificados como la desnudez, la esterilización y el aborto forzados y otras formas de violencia sexual; si las pruebas no eran contundentes, el autor de los hechos quedaba impune.

En este contexto se promulgó la Ley 1719 de 2014, en la que se modifica el Código Penal colombiano, específicamente en cuanto al acceso a la justicia de las víctimas de delitos de violencia sexual en el marco del conflicto armado. Precisa los canales de atención y las responsabilidades institucionales para su abordaje, que incluyen la prohibición de ser adelantadas por la justicia penal militar, en su Artículo 20.

La norma tipifica nuevas conductas estrictamente relacionadas con el conflicto e invierte la carga de la prueba que ahora deberá recaer en el Estado. Asimismo,

Colombia, Congreso de la República, Ley 1257 de 2008, "Por la cual se dictan normas de sensibilización, prevención y sanción de formas de violencia y discriminación contra las mujeres, se reforman los Códigos Penal, de Procedimiento Penal, la Ley 294 de 1996 y se dictan otras disposiciones" (Bogotá: Diario Oficial núm. 47 193, 4 de diciembre de 2008), art. 2. 
incorpora las causales del Estatuto de Roma, junto con la categoría de imprescriptibilidad de estas conductas. ${ }^{40}$ Fija medidas para la conducción de la investigación y apreciación de las pruebas en casos de violencia sexual, una de las grandes falencias de la Ley 975 de 2005, derroteros que incluyen:

1. El no condicionamiento de la determinación de la ocurrencia del hecho de violencia sexual a la existencia de prueba física.

2. La ausencia de rastros de espermatozoides, fluidos, $A D N$ o lesiones en el cuerpo de la víctima no es razón suficiente para concluir la no ocurrencia de la conducta.

3. La utilización de preservativo por parte del presunto agresor no permite inferir el consentimiento por parte de la víctima.

4. El hallazgo del himen entero en la víctima no es razón suficiente para concluir la no ocurrencia de la conducta.

5. Se atenderá al contexto en el que ocurrieron los hechos criminales y los patrones que explican su comisión, en especial aquellos que suceden en el marco del conflicto armado. Para este efecto, los operadores de justicia podrán acudir a peritajes psicológicos o antropológicos.

6. No se desestimará el testimonio de la víctima de violencia sexual con ocasión del conflicto armado, en particular cuando se trate de una víctima menor de edad.

7. Se introducirán técnicas de investigación de alta calidad para obtener pruebas, sin que sean degradantes para la víctima y que minimicen toda intrusión en su intimidad.

8. Ante la existencia de una víctima con orientación sexual diversa, se investigarán a profundidad los hechos ocurridos, sin calificarlos a priori como crímenes pasionales o venganzas personales. La investigación debe garantizar la hipótesis de la existencia del crimen por homofobia.

40 Colombia, Congreso de la República, Ley 1719 de 2014, "Por la cual se modifican algunos artículos de las Leyes 599 de 2000, 906 de 2004 y se adoptan medidas para garantizar el acceso a la justicia de las víctimas de violencia sexual, en especial la violencia sexual con ocasión del conflicto armado, y se dictan otras disposiciones" (Bogotá: Diario Oficial núm. 49 186, 18 de junio de 2014), art. 16. 
La Ley 1719 resulta fundamental porque insta a la creación del Registro unificado de casos de violencia contra la mujer, con el objetivo de "conocer la dimensión de la violencia sexual de que trata la presente ley, monitorear los factores de riesgo de la misma, y aportar elementos de análisis para evaluar las medidas adoptadas en materia de prevención, atención y protección". ${ }^{41}$

En el mismo año de promulgación de la norma se emitió una de las decisiones judiciales más relevantes en el tema de reconocimiento de víctimas de violencia sexual por parte de los grupos paramilitares, el llamado "Fallo macro", que condenó a ocho años a Salvatore Mancuso y once excomandantes de los Bloques Catatumbo, Norte, Córdoba y Montes de María, de las AUC.

La providencia recoge más de 150 testimonios de víctimas e indica que la violencia contra la mujer y los abusos sexuales "eran prácticas que si bien no se determinaban como políticas que hubiesen tenido una directriz general por parte de los comandantes, sí encontraban un componente en común, pues se realizaron, ejecutaron y/o fueron toleradas por los comandantes del Bloque Catatumbo". ${ }^{42}$

Así mismo, se conmina a la Unidad administrativa especial para la atención y la reparación integral de las víctimas a implementar un programa de atención psicológica individualizada para las víctimas del conflicto armado, que sea especializado, coordinado con el Ministerio de Salud y desarrollado por las Secretarías Departamentales y Municipales de Salud que hayan recibido capacitación en temas de conflicto armado y que se ubiquen en los lugares de origen de las víctimas, sino a que:

Dispongan lo necesario para que las diferentes entidades que administran o participan del sistema de seguridad social en salud a nivel nacional, departamental y municipal, sean informadas del padecimiento de las víctimas del conflicto armado y en esa medida privilegien y presten los servicios médicos necesarios para atender las secuelas físicas y psiquiátricas de las víctimas así no estén cubiertas estas personas por el régimen subsidiado de salud al que se encuentren afiliados. Los costos de este procedimiento deberán estar a cargo del Fondo de Solidaridad y Garantías FOSYGA. ${ }^{43}$

\footnotetext{
Colombia, Congreso de la República, Ley 1719 de 2014, 31.

42 Tribunal Superior del Distrito Judicial de Bogotá, Sala de Justicia y Paz, Sentencia del 31 de octubre de 2014 Radicación: 11001600253200680008 , M. P. Alexandra Valencia Molina.

43 Tribunal Superior del Distrito Judicial de Bogotá, Sala de Justicia y Paz, Sentencia del 31 de octubre de 2014.
} 


\section{Conclusiones}

A pesar de los avances en el tema, persisten grandes vacíos en el modo de abordar y comprender el concepto mismo de violencia sexual, sobre todo en el marco del conflicto interno. El fenómeno aún resulta problemático y reviste múltiples dimensiones, pues se ejerce con el objetivo de someter, intimidar, humillar, agredir física, psicológica y socialmente a la víctima y generar terror en el sujeto pasivo, en su familia y en la comunidad a la que pertenece.

Se ha buscado recoger, de manera más expresa, dichas manifestaciones múltiples de la violencia sexual en el Código Penal, especial desde la Ley 1719 de 2014, que complementa lo ya reconocido por la Ley de justicia y paz. Sin embargo, existen significativas ambigüedades en el lenguaje, por ejemplo, en el evento de acto sexual violento, ante inexistencia manifiesta de violencia en situaciones de acercamiento sexual inadecuado como felación, manoseo, exhibicionismo, obligar a mirar, estimulación de genitales, entre otras conductas; aún no se tiene desarrollo jurídico, sanción y pena correspondientes, es decir, se pierde su peso cuando se adelanta la valoración y el registro de la agresión por las instancias competentes, lo que fortalece la impunidad.

Tales imprecisiones se manifiestan con más notoriedad cuando se vinculan a conflictos armados internos prolongados; en este caso, además, deberían implicar mayor participación de las comunidades en torno a la construcción de memoria histórica encaminada a definir la normatividad interna de diversas manifestaciones de violencia sexual que se presentan en Colombia, sin distinción de género. Todo ello con el objetivo de evitar que muchos de estos delitos queden en la impunidad o que, con un criterio de generalidad en el momento de interpretar la ley, se vicie su aplicación y se minimice la intencionalidad en el momento de la comisión.

Por otra parte, al analizar el comportamiento de los perpetradores, en el caso de la violencia sexual ejercida por los paramilitares, se observa su utilización como claro método de guerra, a la luz del derecho internacional humanitario, y como parte integral del modus delictivo de la organización.

Al estudiar los vínculos entre este y otro tipo de delitos atroces cometidos por ese grupo, se identifican dos estrategias encaminadas a la expansión del poder territorial: por un lado, el exterminio de una población, bien sea mediante su desaparición total mediante la ejecución de un alto número de víctimas o la generación de 
altos grados de desplazamiento; por otro, al tomar en cuenta la forma de ejercer de la violencia sexual, se apunta la subordinación y la desarticulación de las redes sociales, por lo que constituye un mecanismo para intimidar a la población como estrategia de guerra.

Puesto que la violencia sexual es una herramienta de manifestación del conflicto, se hace indispensable iniciar una revisión sobre la construcción epistemológica, antropológica, histórica y psicosocial que aborde el fenómeno con los estándares del derecho internacional, para evitar la impunidad del delito y garantizar los derechos de verdad, justicia y reparación de las víctimas.

Tras la revisión efectuada se concluye que, a pesar de los recientes desarrollos normativos y jurisprudenciales y con la existencia de recursos administrativos, investigativos, jurídicos y psicosociales para la atención de las víctimas, los niveles de impunidad resultan alarmantes.

Se reitera que es indispensable que las víctimas cuenten con procesos de intervención psicosocial integral, por cuanto no existen metodologías efectivas erigidas en el reconocimiento del sufrimiento de la víctima que procuren su resarcimiento más allá del logro de la indemnización monetaria y que permitan un acompañamiento real durante todo el proceso judicial.

Se requiere superar la dificultad existente para estudiar el fenómeno, mediante la participación de los tres poderes del Gobierno -Ejecutivo, Legislativo y Judicial-y el sector salud, para hacer un abordaje integral e interdisciplinario, con herramientas para hacer una medición completa y unificada, desde el escenario gubernamental sobre el alcance, la magnitud y la prevalencia de este delito y sus múltiples manifestaciones.

\section{Referencias}

Castaño, José. "Los abusos de la guerra". Semana, Sec. Conflicto armado, agosto 6, 2010. Chaparro M., Liliana. "Ley de Justicia y Paz. Se perpetúa la impunidad de los crímenes sexuales y de género cometidos contra las mujeres" en iJusticia desigual? Género y derechos de las víctimas en Colombia, coordinado por Margarita Bueso, 85-116. Bogotá: Fondo de las Naciones Unidas para la mujer, 2019. 
Colombia, Congreso de la República. Ley 1257 de 2008, "Por la cual se dictan normas de sensibilización, prevención y sanción de formas de violencia y discriminación contra las mujeres, se reforman los Códigos Penal, de Procedimiento Penal, la Ley 294 de 1996 y se dictan otras disposiciones”. Bogotá: Diario Oficial núm. 47 193, 4 de diciembre de 2008.

Colombia, Congreso de la República. Ley 1719 de 2014, "Por la cual se modifican algunos artículos de las Leyes 599 de 2000, 906 de 2004 y se adoptan medidas para garantizar el acceso a la justicia de las víctimas de violencia sexual, en especial la violencia sexual con ocasión del conflicto armado, y se dictan otras disposiciones”. Bogotá: Diario Oficial núm. 49 186, 18 de junio de 2014.

Colombia, Congreso de la República. Ley 975 de 2005, "Por la cual se dictan disposiciones para la reincorporación de miembros de grupos armados organizados al margen de la ley, que contribuyan de manera efectiva a la consecución de la paz nacional y se dictan otras disposiciones para acuerdos humanitarios". Bogotá: Diario Oficial núm. 45980,25 de julio de 2005.

Colombia, Corte Constitucional. Auto 092 de 14 de abril de 2008. M. P. Manuel José Cepeda Espinosa.

Colombia, Corte Constitucional. Auto 092 de 2008. M. P. Manuel Cepeda, Jaime Córdoba y Rodrigo Escobar.

Colombia, Presidencia de la República. Decreto 4760 de 2005. "Por el cual se reglamenta parcialmente la Ley 975 de 2005”. Bogotá: Diario Oficial núm. 46 137, 30 de diciembre de 2005.

Convención sobre la eliminación de todas las formas de discriminación contra la mujer [Cedaw]. Recomendación general No 19. Nueva York, 29 de marzo de 1992.

Corporación Sisma Mujer. Mujeres en conflicto: violencia sexual y paramilitarismo. Bogotá: Litoxpress, 2009.

Corte Interamericana de Derechos Humanos. Sentencia del 15 de junio de 2005. Caso de la Comunidad Moiwana vs. Suriname.

Corte Penal Internacional. Estatuto de Roma. Roma, 17 de julio de 1998.

Corte Penal Internacional. Reglas de procedimiento y prueba. Nueva York, Corte Penal Internacional, 2013.

Cortés, Sonia. "Derechos humanos en las políticas de paz y posconflicto en Colombia". Vía Inveniendi et Iudicandi 11, núm. 1 (enero-junio 2016): 129-145, https://revistas. usantotomas.edu.co/index.php/viei/article/view/2926 (acceso enero 3, 2018).

Gallego, Joaquín. "Paradoja y complejidad de los derechos humanos en la sociedad moderna. Sentido y comunicación”. IUSTA 1, núm. 40 (enero-junio 2014): 143-165, https:// revistas.usantotomas.edu.co/index.php/iusta/article/view/2453 (acceso enero 5, 2018). 
Mesa de Seguimiento al Auto 092 de la Corte Constitucional. Acceso a la justicia para mujeres víctimas de violencia sexual. Cuarto informe de seguimiento al Auto 092 de la Corte Constitucional. Bogotá: Anthropos, 2011.

Organización de las Naciones Unidas [ONU], Consejo de Seguridad. Resolución 1820 de 2008. Nueva York, 19 de junio de 2008.

Organización de las Naciones Unidas [ONU], Consejo de Seguridad. Resolución 1888 de 2009. Nueva York, 30 de septiembre de 2009.

Organización de las Naciones Unidas [ONU], Consejo de Seguridad. Resolución 1960 de 2010. Nueva York, 16 de diciembre de 2010.

Organización de las Naciones Unidas [ONU], Consejo de Seguridad. Resolución 1325 de 2020. Nueva York, 31 de octubre de 2020.

Organización de las Naciones Unidas [ONU]. Declaración sobre la eliminación de la violencia contra la mujer. Nueva York, 20 de diciembre de 1993.

Organización de las Naciones Unidas [ONU]. Declaración y plataforma de acción de Beijing. Beijing, 15 de septiembre de 1995.

Organización de las Naciones Unidas [ONU]. Protocolo facultativo de la Convención sobre eliminación de todas las formas de discriminación contra la mujer. Nueva York, 6 de octubre de 1999.

Organización de los Estados Americanos [OEA]. Convención interamericana para prevenir, sancionar y erradicar la violencia contra la mujer "Convención de Belém do Pará”. Belém do Pará, 9 de junio de 1994.

Portal, Diana. Violencia sexual en conflictos armados: evolución del derecho y el acceso a la justicia de las mujeres. Lima: Demus, Estudio para la defensa de los derechos de la mujer, 2008.

Quiroz, María. "Un acercamiento a las 'oposiciones paradigmáticas' entre neoconstitucionalismo y positivismo jurídico”. IUSTA 1, núm. 41 (junio-septiembre 2014): 77-97, https:// revistas.usantotomas.edu.co/index.php/iusta/article/view/2470 (acceso enero 15, 2018).

Sistema Integrado de Información de Violencias de Género. "Indicadores de violencia sexual". https://cutt.ly/Qn9fj4W (acceso noviembre 5, 2020).

Tribunal Superior del Distrito Judicial de Bogotá, Sala de Justicia y Paz. Sentencia del 31 de octubre de 2014 Radicación: 11001600253200680008 . M. P. Alexandra Valencia Molina. 